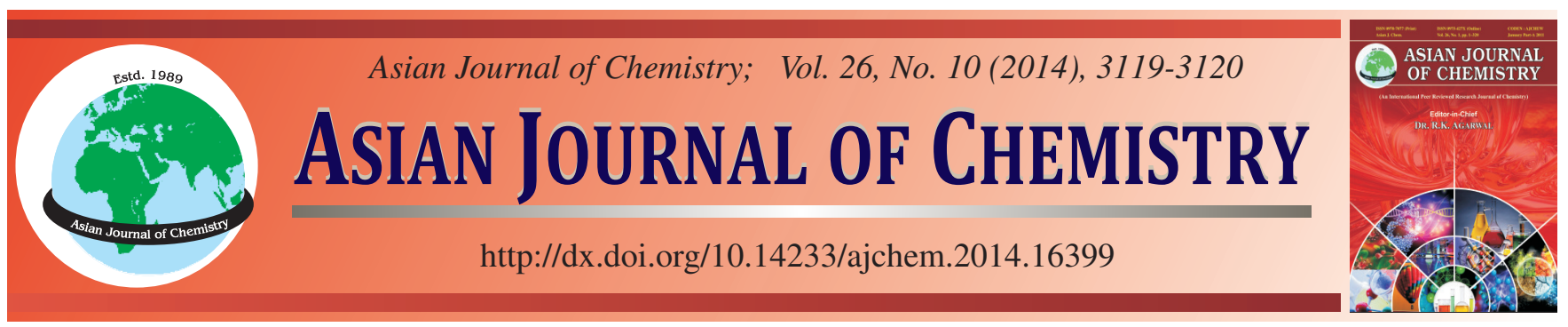

NOTE

Rapid Analysis Method of Water in Cigarette Addictive by Karl Fischer Method

Ji-BaO CAI ${ }^{1}, \mathrm{HAI}-\mathrm{TAO} \mathrm{LuO}^{1}$ and Chang-Li ZhaO ${ }^{2, *}$

${ }^{1}$ Center of R\&D, China Tobacco Jiangxi Industrial Co. Ltd., Nanchang 330096, P.R. China

${ }^{2}$ School of Education, Nanchang University, Nanchang 330031, P.R. China

*Corresponding author: E-mail: jbcai@ustc.edu.cn

Received: 20 September 2013;

Accepted: 9 December 2013;

Published online: 10 May 2014;

AJC-15193

The rapid analytical method to determine the trace of water in tobacco essence by Karl Fischer method. The results showed water in cigarette addictive was determined, respectively by Karl Fischer method with satisfactory results. The RSD of this determination method was $1.65-2.54 \%$ and recovery rate reached $93.46-106.15 \%$. This method has been applied for the determination of water in cigarette addictive. The content of total water was $1.49-5.74 \%$.

Keywords: Cigarette addictive, Water, Determination, Karl fischer method.

Cigarette tobacco flavor was indispensable raw material in tobacco production and tobacco flavor technology was one of the core technologies in tobacco industry, closely related with the cigarette brand building and development. Therefore, chemical composition accurate qualitative and quantitative analysis of tobacco flavor had a very important significance ${ }^{1,2}$. Tobacco flavors routine testing could refer to the state tobacco industry standards ${ }^{3,4}$. As we know, many researchers focus on the aroma components ${ }^{5,6}$ and heavy metals ${ }^{7,8}$ in tobacco flavor. However, as the largest component in tobacco flavor, solvent was one of the important parts of flavor product analysis. Because of the certain significance of solvent composition in product stability and eligibility, determination of the solvent in tobacco flavors had important implication.

Compared to density, refractive index and other conventional test methods, Karl Fischer method ${ }^{9,10}$ can detect fragrance changes of water more accurately in tobacco flavor. Obvious advantages are as follows: (1) Karl Fischer method can accurately individually measured flavors subtle changes in the water, while the density, refractive index and other indicators is difficult to do. (2) Karl Fischer method can quickly determine the water contents of flavors and fragrances, which is also a valuable reference in product analysis.

Currently, there are not many methods determining the water content in flavour and fragrance. Liu et al. ${ }^{11}$ had determined the moisture using gas chromatography. The whole process takes only $12 \mathrm{~min}$, but water can't completely separate from methanol. In this paper, the Karl Fischer method was used for the determination of the four kinds of Hongta group tobacco flavors. The experiment operation is simple, can also be a valuable reference of water determination in tobacco essence.

Karl Fischer reagent (Karl Fischer reagents, pyridine-safe, titer $\mathrm{E}=3-5 \mathrm{mg} / \mathrm{mL}$, Shanghai New Chemical Technologies, Inc.); isopropanol (purity $=99.7 \%$, the highest moisture content of $0.2 \%$, Shantou West Long Chemical Plant); anhydrous methanol (purity $=99.5 \%$, the highest moisture content of $0.05 \%$, Tianjin Chemical reagent Factory); distilled water; KF701 type of trace moisture analyzer (Switzerland Titrino Metrohm company); BT224S analytical balance (0.0001 g, Beijing Sartorius Scientific Instruments Co., Ltd.).

Determination of water: The principle of Karl Fischer is the reaction used coulometric titration to determine the amount of water in a sample. The reaction involves converting solid iodine into hydrogen iodide in the presence of sulfur dioxide and water. Methanol is most often used as the solvent, but ethylene glycol and diethylene glycol also work. Pyridine is often used to prevent the build up of sulfuric acid, although the use of imidazole and diethanolamine for this role are becoming more common. All reagents must beanhydrous for the analysis to be quantitative. The balanced chemical equation was:

$$
\begin{gathered}
\mathrm{H}_{2} \mathrm{O}+\mathrm{I}_{2}+\mathrm{SO}_{2}+3 \mathrm{C}_{5} \mathrm{H}_{5} \mathrm{~N} \longrightarrow 2 \mathrm{C}_{5} \mathrm{H}_{5} \mathrm{~N} \cdot \mathrm{HI}+\mathrm{C}_{5} \mathrm{H}_{5} \mathrm{~N} \cdot \mathrm{SO}_{3} \\
\mathrm{C}_{5} \mathrm{H}_{5} \mathrm{~N} \cdot \mathrm{SO}_{3}+\mathrm{CH}_{3} \mathrm{OH} \longrightarrow \mathrm{C}_{5} \mathrm{H}_{5} \mathrm{~N} \cdot \mathrm{HSO}_{4} \mathrm{CH}_{3}
\end{gathered}
$$

\section{Measured steps}

(A) Automatic pre-titration: titrated water in methanol to the end using Karl Fischer reagent, keeping the titration cell waterless. 
(B) Card's reagent calibration: Taken $10 \mu \mathrm{L}$ of distilled water by micro-syringe, weighed accurately and record the amount of injection of distilled water. Titrate using Karl Fischer reagent, calculate the titer value $(\mathrm{E})$. Each sample was first calibrated before the measurement $\mathrm{E}, \mathrm{E}$ in each deviation does not exceed $0.5 \%$ of the average.

$$
\mathrm{E}=\mathrm{M} / \mathrm{V}
$$

E-Karl Fischer reagent titer $(\mathrm{mg} / \mathrm{mL})$;

M-Distilled water quality (mg);

V-Titrated volume of Karl Fischer reagent (mL).

(C) Background determination: Titrated moisture in the environment to eliminate the impact on the determination results. Measured value is automatically saved and automatic correct when determined sample.

(D) Determination of water content: Weigh a certain quality of the sample, quickly added to the reaction flask and titrated, recorded Titrate card's reagent volume consumed (V).

Repeat each determination twice.

$$
\text { Moisture content of tobacco flavors (\%) }
$$$$
=\mathrm{V} \times \mathrm{E} \times 100 \% /(\mathrm{M} \times 1000)
$$

V-Consumption volume of Karl Fischer reagent titrate $\mathrm{V}, \mathrm{mL}$

E-Titre of Karl Fischer reagent, $\mathrm{mg} / \mathrm{mL}$, M-weight of the sample, $g$

Weigh $1.2500 \mathrm{~g}$ distilled water. Prepared $25 \mathrm{mg} / \mathrm{mL}$ standards liquor of water. The mother liquor was diluted with a stock solution of $0,0.5,1,2,3,4,5 \mathrm{mg} / \mathrm{mL}$ standard solution. Pipette $5 \mathrm{~mL}$ standard solution each, titrated and measured respectively using the Karl Fischer method, noted the card's reagent consumption and corresponding water quality. Using the above data to regression analysis, the working curve regression equation was: $\mathrm{y}=0.6784+1.3839 \mathrm{x}, \mathrm{r}=0.9993$ (Fig.1).

Determination of detection limit: Least three different concentrations of the standard solution of water were measured six times. And each concentration's standard deviation s1, s2, s3 was calculated. Using standard deviation and concentration to linear regression analysis, the regression equation was: $\mathrm{s}=$ $-0.051 \mathrm{x}+0.1173 \mathrm{R}=0.9997$. When $\mathrm{x}=0, \mathrm{~s} 0=0.1173$. As the result, three times detection limit was $0.35 \mathrm{mg} / \mathrm{mL}$. Therefore, this method is more sensitive.

Recovery and repeatability: Added $2 \mathrm{~mL}$ water standard of $2 \mathrm{mg} / \mathrm{mL}$ each sample, measured water content by this method. Calculate recovery according to the amount of standard sample, after added standard sample. Because of the high recovery (93.43-106.10\%), this method showed high accuracy.

Determination tobacco flavor parallels six times use the method above and calculated standard deviation. The results showed that the RSD were less than $5 \%$, indicating good reproducibility of the method.

Results of sample analysis: Four kinds of tobacco flavors of Hongta group were determined water content by Karl Fischer assay (Table-1). The experimental results showed that: the water content of different flavors was significantly different, was $1.49-5.74 \%$.

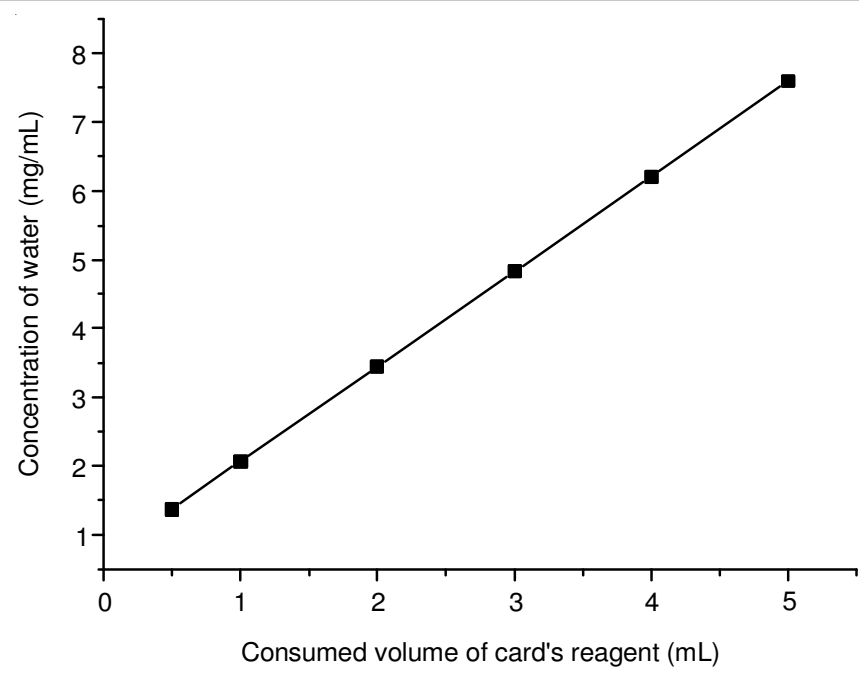

Fig.1. Working curve regression equation. X-the consumed volume of card's reagent $(\mathrm{mL})$; Y-the concentration of water $(\mathrm{mg} / \mathrm{mL})$

\begin{tabular}{cccc}
\multicolumn{4}{c}{ TABLE-1 } \\
WATER CONTENT OF FOUR KINDS OF \\
TOBACCO FLAVORS OF HONGTA GROUP \\
\hline \multirow{2}{*}{ Flavor name } & $\begin{array}{c}\text { Flavor weight } \\
(\mathrm{mg})\end{array}$ & $\begin{array}{c}\text { Titrated volume } \\
\text { of Karl 's } \\
\text { reagen }(\mathrm{mL})\end{array}$ & $\begin{array}{c}\text { Water content } \\
(\%)\end{array}$ \\
\hline \multirow{2}{*}{ 40902A011-1 } & 216.9 & 1.109 & 1.94 \\
4092A011-2 & 185.5 & 0.896 & 1.83 \\
& 99.7 & 0.426 & 1.62 \\
4092A011-3 & 174.2 & 0.734 & 1.60 \\
& 158.6 & 0.624 & 1.49 \\
4092A011-4 & 210.0 & 0.839 & 1.52 \\
& 201.6 & 3.053 & 5.74 \\
\hline
\end{tabular}

Karl Fischer titration degrees of this experimental: $E=3.7913 \mathrm{mg} / \mathrm{mL}$

\section{Conclusion}

Karl Fischer method is a desirable method for rapid water analysis in tobacco flavor. The RSD of this determination method was 1.65-2.54\% and recovery rate reached 93.46$106.15 \%$. This method has been applied for the determination of water in tobacco flavor. The content of total water was 1.49 $5.74 \%$.

\section{REFERENCES}

1. C. Jiang, H. Yang and L. Wang, J. Instr. Anal., 304, 301 (2007).

2. X. Wan, M. Tian and K. Row, Asian J. Chem., 21, 5999 (2009).

3. H. Liao, Y. Zhang and Y. Zhuang, Chinese J. Tobacco, 8, 8 (2008).

4. E. Soleymani and M. Meshkatalsadat, Asian J. Chem., 22, 5244 (2010).

5. J. Shi, L. Li and Q. Hu, Tobacco Sci. Tech. (Paris), 12, 262 (2006).

6. N. Jyothi, N. Farook, M. Cho and J. Shim, Asian J. Chem., 25, 4125 (2013).

7. Y. Zhang, Q. Yin and H. Zhou, Tobacco Sci. Technol., 12, 571 (2006).

8. A.N. Garg and K. Verma, Asian J. Chem., 24, 5435 (2012).

9. M. Yu and R. Li, Tobacco Sci. Technol., 6, 282 (1998).

10. B.D. Sahinbaskan, E. Torgan and R. Karadag, Asian J. Chem., 23, 5441 (2011).

11. H.-W. Liu, Y.-T. Liu, B.-Z. Wu, H.-C. Nian, H.-J. Chen, K.-H. Chiu and J.-G. Lo, Talanta, 80, 903 (2009) 